\title{
Public-Private Collaboration in the Emergence of a National Electronic Identification Policy: The Case of NemID in Denmark
}

\author{
Rony Medaglia \\ Department of IT Management \\ Copenhagen Business School \\ Frederiksberg, Denmark \\ rm.itm@cbs.dk
}

\author{
Jonas Hedman \\ Department of IT Management \\ Copenhagen Business School \\ Frederiksberg, Denmark \\ jh.itm@cbs.dk
}

\author{
Ben Eaton \\ Department of Technology/IT \\ Westerdals Oslo ACT \\ Oslo, Norway \\ eatben@westerdals.no
}

\begin{abstract}
Governments envisioning large-scale national $e$ government policies increasingly draw on collaboration with private actors, yet the relationship between dynamics and outcomes of public-private partnership $(P P P)$ is still unclear. The involvement of the banking sector in the emergence of a national electronic identification (e-ID) in Denmark is a case in point. Drawing on an analysis of primary and secondary data, we adopt the theoretical lens of collective action to investigate how transformations over time in the convergence of interests, the interdependence of resources, and the alignment of governance models between government and the banking sector shaped the emergence of the Danish national e-ID. We propose a process model to conceptualize paths towards the emergence of public-private collaboration for digital information infrastructure - a common good.
\end{abstract}

\section{Introduction}

Facing complex societal challenges, public agencies are increasingly establishing collaboration with private actors in order to realize policy objectives [18]. In particular, governments involve private actors for establishing digital infrastructures by adopting publicprivate partnership (PPP) arrangements [9,12,37]. Benefits from PPP have been argued to include increased efficiency in project management, cost reduction, risk sharing, improvement of service quality, and enhanced technological innovation [3,25,27].

The case in this paper is the emergence of a national electronic ID (e-ID). e-ID initiatives are especially interesting, since the authentication of citizens has traditionally been an area of exclusive responsibility of state bureaucracies [2]. With the booming diffusion of citizen access to digital infrastructure, governments across the world are now experimenting with adopting technologies for the identification of citizens in the digital realm, in order to guarantee access and authentication for welfare services, and to achieve administrative cost-savings. In this way, private actors, such as banks, have come to play a crucial role in the design, management, and implementation of such technologies, whereby both the financial and the public actors can obtain strategic benefits.

Collaboration, negotiation, and conflict between private and public actors can be expected to shape the emergence of shared digital infrastructure such as those concerning a national e-ID policy. The influence of the characteristics of the interplay between public and private actors on the nature of the emerging technologies thus assumes key relevance. However, from a research point of view, how the dynamics of interactions between public and public sector evolve over time and result in a particular shared technology is still unclear.

This paper thus aims at tackling the research question: how does the interaction between private and public actors influence the emergence of national e-ID?

To answer this research question, we investigate the interplay between the banking sector and government in the emergence of the Danish national electronic identification - NemID. We adopt a retrospective case study to infer generalizable insights concerning interactions between private and public actors in the emergence of a shared digital infrastructure.

To analyze the empirical material, we draw on the theoretical lens of collective action to unpack the transformation of interests, resources, and governance of relationships between the government and the banking sector over time. The theory of collective action is a means of explaining broad conditions under which actors are able to collaborate with each other in order to establish a common good.

The paper is structured as follows. In the next section we discuss research on public-private collaboration in egovernment policies, and previous studies on e-ID. In section 3 we present the theoretical framework of collective action. In section 4 we present the methods used for collecting and analyzing the empirical data. In section 5 we then outline the details of the emergence of 
national e-ID in Denmark. In section 6 we illustrate how interests, resources, and governance of relationships between governments and the banking sector changed over time, distinguishing between three phases of transformation. We then propose a dialectic process model describing the emergence of national e-ID that extends on the collective action theory. In the discussion section we highlight contributions of the study to research and practice and its limitations, and in the conclusion section we summarize the content of the study.

\section{Background and previous research}

\subsection{Public-private collaboration in e- government policies}

Public agencies seek to benefit from the establishment of PPP arrangements in devising public policies. Benefits of PPPs have been found to include increased efficiency in project management, cost reduction, risk sharing, improvement of service quality, and enhanced technological innovation [3,25,27]. In particular, governments seeking to utilize digital infrastructures effectively, increasingly draw on PPP arrangements in pursuing e-government initiatives [9].

Despite this growing phenomenon, relatively few empirical studies tackle the interaction between the public and private sector in e-government initiatives [41]. These have mainly focused on three aspects: antecedents, effects, and governance of PPPs in egovernment initiatives.

Studies focusing on antecedents of PPPs in egovernment aim at highlighting generic success factors of collaboration for e-government initiatives [41]. Studies on the effects of PPP-enabled e-government initiatives focus on how these collaborations result in power shifts between the actors involved [1].

On the other hand, a number of studies have focused on the mechanisms of governance enacted in egovernment PPPs. Drawing on an analysis of publicprivate information platforms, it has been suggested that, from a government perspective, striking the right balance between maintaining the control needed to secure public value, and enabling autonomy that can encourage innovation, is of key importance [17]. Similarly, the achievement of goals of governance networks, in which government, business, and civic actors alike take part, is deemed to be affected by network strategies and structures, including design and human capital [31].

While research on the relationships between public and private actors engaged in the establishment of egovernment initiatives grows - as it strives to keep up with the expansion of PPPs in e-government policymaking - there are still some key research gaps. The majority of existing studies takes a snapshot view of the observed phenomena, and fall short of accounting for causal links between the nature of the observed PPPs and the implemented e-government solutions. There is thus need for further research on: a) how the dynamics of interaction between the public and private actors evolve over time (i.e., longitudinal perspectives); b) how the characteristics of the evolution of PPP over time result in a specific e-government technology; and c) a more abstract view (e.g., in the form of a process model) to account for these phenomena, and to formulate testable propositions.

\subsection{Electronic identification (e-ID)}

Paralleling the growing research interest in how public and private actors interact in the development of shared digital infrastructures, there is also a maturing body of research on e-ID [44]. E-IDs have been studied from many perspectives, including technological decision [45], trust and public value [40], surveillance [23], security [46], historical evolution [14], legal framework [22], innovation process [19,20], market governance [10], and life cycle [26]. In this body of research a variety of theories - such as innovation $[19,20]$ and boundary object $[13]$ theories - and methods - such as case studies [13,14], and surveys [40] - have been applied.

Particularly relevant to this study is research that provides insights into the evolution of e-ID. Grönlund [10], for instance, found that the development of e-ID could be driven by governmental actors as well as by market actors [10]. Another set of studies from Sweden focus on the development of national e-ID from a life cycle perspective [26]. Melin et al. [26] found that there are significant challenges involved in managing e-ID, mainly due to contextual, technological integration, and governance issues in these projects. However, the dynamics between the actors and how the dynamics evolve over time are still unclear.

\section{Theoretical framework}

The theory of collective action is a means of explaining broad conditions under which actors are able to collaborate with each other in order to establish a common good. The key concern is how different groups coordinate when they may have different interests, conflicting resources, and tendencies to free ride on the efforts of others.

The theory was first put forward by Olson [33] and has subsequently found widespread adoption in the social sciences [35,38]. Collective action has found 
particular application in information systems (IS) studies, where the goal has been to understand how shared information infrastructures can emerge, for example: amongst groups of banks and mobile operators attempting to establish a common mobile payments platform [39]; in public healthcare providers and private R\&D institutions establishing a regional health information infrastructure [4]; and in the emergence of industry-wide IS standardization in the residential mortgage industry [24]. These perspectives and the sources that they draw upon inform our analysis. Studies of collective action directed at producing common IS goods are characterized by analyzing the socio-technical arrangements around three key factors: 1) the interests, 2 ) the resources, and 3) the governance of contributing actors [4,24,39].

The various interests of the group of actors contributing to establish the collective IS good may be both economic, such as deriving commercial profit, and non-economic, such as gaining knowledge [28]. Heterogeneous interests can bring conflicts of interest amongst different members, which can become problematic for collective action to occur [16]. Consequently, it becomes necessary to reconcile divergent interests of a group to ensure participation [24]. In contrast, convergent interests amongst a group facilitate cooperation to establish a common IS good.

The range of technical, financial and organizational resources that are brought in and shared, contributing to establish a common IS good, are also of importance [29]. The participation of particular actors becomes necessary because of the unique resources that they bring and which are required for the cooperation to work [24]. The more heterogeneous the distribution of key resources is across the collaborating organizations, the more mutually interdependent they are upon each other in order to establish the collective IS good. On occasion, network effects created by the participation of multiple members can be a driver for essential resources such as installed base.

The governance and coordination of organizations contributing to a common shared common digital infrastructure emerges as the final key factor. This function is typically carried out under the leadership of a central authority [7,24]. The task of establishing collective action is concerned with mobilizing an initial group of contributors and initial activities to generate a bandwagon effect [32]. The initial group of contributors is often a club "with limited numbers of members with homogeneous interests" [8]. Another set of activities concerns the establishment and management of fora where members can discuss and resolve issues. With these activities comes the need to establish rules or policies to guide interactions and the management of resources [24]. These fora provide a means by which members can manage each other, for example through "moral suasion" [7,24], thereby contributing to the governance of the collective.

We adopt the lens of the theory of collective action to unpack how the transformations of the interplay of interests, resources, and governance between public and private actors over time result in the emergence of a shared digital infrastructure - in this case, a national eID policy.

\section{Method}

We adopt a qualitative approach and conducted a retrospective case study $[36,48]$. The case we have chosen, the emergence of e-ID in Denmark, has given us the opportunity to explore a phenomenon that was rarely explored before, namely the relationship between private institutions and the public sector in the emergence of e-ID. Our methodological stance is interpretive in that we used texts reflecting the subjects' experiences with the process to develop a second-order theoretical understanding of the phenomenon [43].

\subsection{Data collection}

The data for this study was collected from three main sources to trace the emergence of e-ID: 1) online sources, including organizational blog posts; 2) documents, including policy documents, legal framework and associated documents; and 3) interviews with key stakeholders chosen on the basis of their expertise, in line with the key informant approach [21]. The objective was to identify relevant initial conditions, changes, events, and states necessary to capture the emergence of e-ID.

\subsection{Data analysis}

We coded the data in three broad (partly overlapping) phases, with distinct objectives. Our unit of analysis concerned the interactions between governments and banks in the establishment of e-ID. The first phase of coding of the data aimed to capture the event-time series of the emergence of e-ID. Coding categories were generic process codes [42], including events, actions, decisions, and outcomes, to determine concepts (such as phases, technologies, policies, stakeholders, user base etc.) and their properties (e.g., initial/final), we applied an open coding procedure [5].

The outcome of the first coding phase was a timeline depicting the emergence of e-ID in Denmark with an unstructured list of concepts that seemed to be relevant in the story that lead to the current situation. The initial findings - for example that e-IDs were initiated by 
banks to allow customers access to the internet banking, new legislation - triggered a second phase of more coding as well as continuous data collection. In the second phase, we approached the emergence of e-ID as a theoretical issue extending and challenging our findings.

Stimulated by the emerging event sequences highlighting the policy makers' role, we turned to the collective action literature for a focal category of coding of the e-ID process. This focal category allowed us to systematically relate the various concepts of e-ID emergence produced in the open coding phase (e.g., "installed base" became "resources", and "legal framework" became "governance"), and from three sources to trace the evolution of e-ID. These emerging themes spurred a new literature search for theoretical arguments supporting empirical findings of dynamic effects following the emergence of e-ID. Concepts were clustered using a constant comparison method [5].

In the third and final phase, we turned yet again the literature and, instead of focusing on focal categories, we looked for overarching patterns. We found inspiration in dialectic theories [42]: thesis, anti-thesis, conflict and synthesis. This enabled us to develop a dialectic process model by tracing the order of events and underlying mechanisms.

In the next section, we present the case on the emergence of e-ID in Denmark.

\section{Case description: The emergence of e-ID in Denmark}

The idea of universal e-ID in Denmark was first presented within the national e-government plan in 1992 [6]. The Ministry of Finance presented the idea of a multi-purpose physical ID card, based on smart card technology, to work as a means of offline visual identification, an electronic key for the Central Person Register (CPR), and a tool for the authorities to access personal information. The vision was to eventually replace all other cards, including social security cards, student cards, and driver licenses. The majority in Parliament, who raised privacy concerns, opposed the proposal. A later proposal in 1996 for an optional card for online authentication failed due to the lack of agreement on a technical standard. As a result, the ambitions from then on were reduced to adopting a system of digital signatures, and not a card.

After a change in the political orientation of the government, competencies for e-government policies were moved to the newly established Ministry of Science, Technology and Innovation. The Ministry published the idea of a "Public Service Net", which gave IT a much more important role in the political discourse than before, but had little practical implications [15]. From 2001 a new government cabinet took over. The Digital Task Force (DTF) was established, a projectbased organization hosted by the Ministry of Finance. The DTF coordinates all entities that are involved in egovernment (central, regional, local government, and businesses). Up to this period, different separate initiatives for authentication to access public services flourished within the public sector, including a regional health card, and two tax system authentication technologies: one based on a one-time password and one that required the installation of a software on the user's device.

In this period, banks started developing their own security solution, known as Net-ID, for access to online banking services. The individual banks under the certification authority of the Pengeinstitutternes Betalings Systemer ("The financial institutes' payment systems" - PBS) issued Net-ID. The Net-ID was developed in isolation from the public sector, and the banks saw little benefit in cooperating with the public sector in this area, except for the use of CPR number as a unique identifier.

The government established its own framework for a national digital signature (Danish law nr. 417 of May $\left.31^{\text {st }}, 2000\right)$, based on an existing EU directive (1999/93/EC), and issued a public tender for the implementation. During the evaluation two vendors were found particularly attractive. The first was a consortium of banks and PBS who were offering NetID. The second was TDC (Tele Denmark Communications), the former national telecom company. After some deliberation, TDC was awarded the contract by the Danish government. The result was a software-based signature for authentication to access online public services. The signature was obtained by entering one's CPR number, postal code, and e-mail address. Activation of the signature required downloading a software on a citizen's device, and using a PIN code sent by physical letter (similar to the banking Net-ID). The roll out of the digital signature was much slower, compared to the banks' Net-ID. In the period 2003-2007 only around 250,000 citizens used this technology, compared to 2.2 million users of Net-ID. The main reason for the low up-take was the absence of a perceived benefit from citizens and businesses, and technical difficulties. For instance, the installation of digital signatures on Mac users was problematic [14].

In 2008, after the contract between TDC and the National Board of IT-and Telecommunications (NBIT) expired, it was time for a new tender. PBS (later renamed to Nets) won this tender. The new solution was called NemID ("EasyID" in Danish), and was characterized by: a) possibility to be used as signature for banking services; b) a two-factor identification 
technology, containing something you know (username/password), and something you get (a onetime password); c) the possibility of logging from multiple devices.

The technology initially encountered criticism, in particular regarding privacy and security. However, this time, learning from the unsuccessful experience, in order to prevent criticism, the Board of IT and Telecommunications tried to integrate civil society concerns by allowing the IT Political Association and the Danish Consumer Council a role in the choice of software and standards. This co-optation strategy resulted in partially assuaging overall criticisms, even though the IT Political Association left the working group established to create the new standards due to dissatisfaction with the results obtained. The NemID became operational in January 2011, and reached 3.5 million users in March 2011, when other legacy identification solutions were stopped [30].

Today, NemID is used by all public institutions and by private actors where secure electronic authentication is needed.

\section{Analysis}

\subsection{The transformation of interest, resources, and governance}

We see the emergence of a national e-ID as an example of the establishment of a common digital infrastructure, which comes about as a result of the interaction between the private sector (the banks) and the government. We focus on the role of interests, resources, and governance, using the collective action theory as an interpretative lens to understand the emergence of e-ID.

\subsubsection{Phase one: no common e-ID technology considered}

Interests. In the first phase the banking sector and the government featured interests that were not aligned. The government was developing the vision of a national e-ID system for their citizens to access e-government services, pursuing their overall interests embedded in the e-government policy plans, concerning maintaining democratic legitimacy, by aiming at providing universal citizen access to digital services, and enabling efficiency, by aiming at cost-saving through streamlining of administrative processes. On the other hand the banks, in developing their own shared authentication infrastructure, pursued other interests. These concerned leveraging economies of scale and being able to generate revenue from other businesses wishing to use the system with a large installed base of users.

Resources. In this early phase there was no significant interdependency of resources between the Danish government and the banking sector with respect to a common e-ID. The banking sector was, however, reliant on the CPR assigned by the government, as a means of identifying users accessing banking services. For the rest, the two actors did not depend on each other's resources in this phase, the government's main resource being the power of legislation, through which to potentially establish the mandatory adoption of the digital signature by the different public agencies; and the banking sector's main resource being their common ownership of financial infrastructure providers, for the design, building and management of their online authentication solutions.

Governance. As the governments and the banks were not yet cooperating, there were no structures in place between these two sides with respect to the governance of a common e-ID. However, the banks had their own governance structures in place, mediated by their respective bankers' associations.

\subsubsection{Phase two: common e-ID desired}

Interests. In this second phase, the government and the banks entered discussions regarding common national e-ID systems. This was driven by the governments' vision of providing citizens with e-ID, while the banks' interests were driven by economies of scale and a potential for increased revenues. However, discussions in Denmark were difficult with respect to which security standards to employ.

Resources. The interdependency of resources between government and the banking sector remains similar at this phase. While resources related to government and bank e-IDs remained strictly independent of each other, the government realized the need for a growing user base for its online authentication system, which banks managed to build up more quickly than the public sector agencies.

Governance. The government established a framework for the governance of a national e-ID, that took the form of a national law built on European Union directives.

\subsubsection{Phase three: common e-ID achieved}

Interests. In this third phase, the interests of the Danish government and the banking industry converged sufficiently for a national e-ID to emerge. The key areas where their interests had diverged were overcome with compromise on both sides: the parties were able to find solutions for their differences over security standards.

Resources. An increasing interdependency of resources between the government and the banking 
sector influenced the launch of a national e-ID. The government found itself dependent on the resource of a wide user base held by banks, while banks developed the need for government's support for expanding the range of application of their authentication system to include digital public service access, and third-party commercial applications.

Governance. Within the legal framework of the regulations drafted by the Danish government to enforce requirements for the tender winners, the government and the banks swiftly established a mechanism based on cooperation. The infrastructures for online banking and digital public services are coordinated under a certification authority, maintained by the bank consortium that won the current tender, and ultimately led by government requirements renewed at every tender cycle.

\subsection{A process model}

The transformation over time of the interplay between interests, resources, and governance of relationships between the banking sector and government in the emergence of national e-ID can be conceptualized as a process model. In particular, the three phases of transformation in the three dimensions that shape collective action assume the form of a dialectic process [42]. The dialectic nature of this process is evident when looking at the three phases of transformation: first, as thesis and anti-thesis when the two groups of actors do not consider a common good and are engaged in parallel developments, each with its own separate configurations of interests, resources, and governance; second, as conflict when the two parties desire a common good, but disagree on how their interests, resources and approach to governance can be aligned; and third, as synthesis when the parties resolve tensions across the dimensions of interests, resources and governance, and a common good can be achieved. Our dialectic process model is represented in Figure 1.

The dynamics that occur between the dimensions of collective action play out across the three phases in the following way.

In the first phase, when government and banks have not yet considered a common e-ID system, each group focuses on its own e-ID plans. Here collective action is not realized between the two parties, but within the members that make up each group. The banks' e-ID is characterized by an interdependency of technical, organizational and installed base resources ( $\mathrm{R}$ in Figure $1)$, driven by convergent economic interests (I) and organized by particular governance $(\mathrm{G})$ arrangements. The government's plans are organized around financial and bureaucratic resources driven by an interest in establishing universal access to online government services and organized through government agencies and policy.

In the second phase government and banks begin to recognize a desire for a common e-ID. However, proposals for a combined technology lead to conflict across the dimensions of collective action that we consider. They cannot agree on a common infrastructure

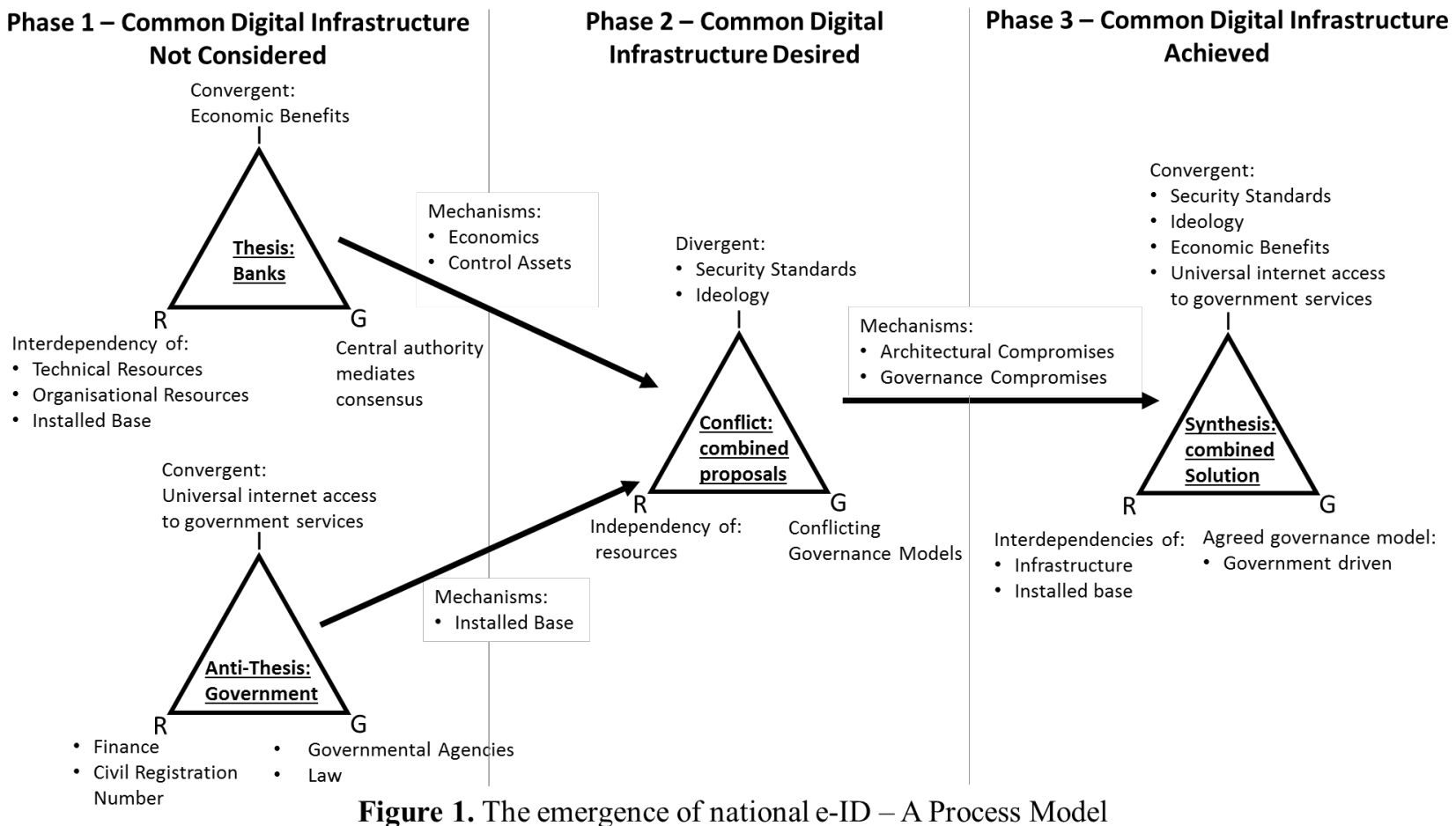


as the divergent interests around security standards and ideology and their disagreements over overarching governance models prevent them from sharing resources, which remain independent.

Finally, in the third phase the government and banks are able to achieve realizable plans for a common e-ID. The common e-ID is characterized by an interdependency of e-ID infrastructure and installed base of users. This interdependency is reached as their interests converge in issues concerning security standards, ideology, economic benefits, and enabling universal internet access to government services. Both the convergence of interests and interdependency of resources is facilitated by agreed overarching models of governance. In the context of Denmark, the agreed governance model that enabled the respective parties to cooperate to realize a system of national e-ID, was driven by government regulation.

We see different groups of mechanisms, which facilitate the transition from one phase to another across our dialectic process model. The banks were able to transition from a phase where they were not considering participation in a national e-ID, to a second phase where they were driven by a desire to establish cost savings through economies of scale and the potential of additional revenues, as well as a realization that they could retain control of assets central to their e-IDs. Similarly, the government transitioned across the two phases once they realized that access to the banks' installed base of users, combined with the public's familiarity with the banks' e-ID authentication processes, would encourage the public's access to government services. Furthermore, it was the ability of the parties to compromise over the architectural approach to realizing a common infrastructure and the way that it is governed that enabled them to realize a national e-ID.

\section{Discussion}

\subsection{Contributions}

In this paper we have explored how the transformation over time of the role of interests, resources, and governance between public and private actors resulted in the emergence of a common e-ID policy in Denmark. Findings contribute to research on PPP in e-government policy-making, to the theory of collective action, and to practice.

First, while research on the relationships between public and private actors engaged in the establishment of e-government initiatives grows, the majority of existing studies takes a snapshot view of the observed phenomena, and fall short of accounting for causal links between the nature of the observed PPPs and the implemented e-government technologies. This study sheds light on how the characteristics of the development of a PPP over time result in the emergence of a specific e-government policy. In particular, our study complements the extant body of knowledge on eIDs, which so far have been analyzed from the perspective of technological decision [45], trust and public value [40], life cycle perspective [26], and market governance [10] but, to the best of our knowledge, never from a PPP or collective action perspective.

Second, findings from the study have implications for theory. Using the lens of collective action, we provided a longitudinal view of how interests, resources, and governance change over time in the interplay between actors, resulting in the emergence of a common good. The analysis of transformations in the distribution of interests and resources, and of modes of governance as a process, led us to identifying a dialectic movement [42] conceptualized in three phases of thesis/antithesis, conflict, and synthesis. This dialectic process model contributes to refining the theoretical lens of collective action itself, by accommodating a process view on the interplay between actors leading to collaboration over time, as opposed to a still representation of the role of interests, resources, and governance. Moreover, this dialectic model contributes to a conceptualization of the interplay between factors that shape the emergence of a collaborative project - e.g., how a common good becomes implemented and absorbed in organizations or in society - in contrast with the assumption of the importance of top-management decisions that dominates much information systems and management research [47], and in line with the shift from traditional and New Public Management, towards a "Networked Governance" model in public administration research $[11,34]$. Such a conceptualization can help frame processes of collective action in future studies involving PPP in e-government.

Third, regarding practice, findings from our study have implications for both public and private organizations' management engaged in collaboration related to common goods. Our study has focused on the role of PPP in helping establish e-ID in the context of just one country, Denmark. However, we have purposely developed a broad model that we hope would fit similar PPP-based e-ID initiatives in other national contexts. In order to cater for other contexts, we suggest that during the key phase of transition from divergent to convergent interests and from independence to interdependency of resources between actors, it is of crucial importance to find ad hoc mechanisms of governance, as opposed to "one size fits all" governance solutions. As this study clearly shows, the conflict and negotiation phases throughout the dialectic process of 
achieving a common good are an integral part of the process of aligning interests and resources, which can also take long periods of time. However, the parties involved should pursue specific governance arrangements that fit the nature of the interests and resources involved, rather than trying to adapt them to a pre-defined governance template. We suggest that there are varying governance modes that can be adopted by managers to successfully accommodate the transformation of interests and resources, and that demonstrating this provides opportunities for future research.

\subsection{Limitations}

As with any research, ours is subject to limitations. It should be clear that historical data do not provide firsthand accounts of the research situation and may be biased and lack details. While our research design offers longitudinal coverage of the emergence of e-ID, data collection on the emergence were collected toward the end of the process. Therefore, it would be useful in the future to include real-time data collection - based on ethnography and other rich data collection approaches since it potentially enriches construct and association conceptualization as it allows for a close-up study of emerging practices and sense-making of stakeholders involved.

\section{Conclusion}

Governments committed to large-scale egovernment policies increasingly draw on collaboration with private actors. However, the relationships between dynamics and outcomes of public-private e-government collaborations is still unclear. In this study, we aimed at answering the research question "How does the interaction between private and public actors influence the emergence of national e-ID?" by carrying out an analysis of the emergence of e-ID in Denmark as the result of patterns of interaction between government and the private sector over time.

Our findings show how a shared e-government policy solution can emerge as the result of the convergence of interests, interdependency of resources, and alignment of governance arrangements between the actors over time. The dialectic process model we propose aims at conceptualizing different paths towards collaboration, by highlighting the role of interests, resources, and governance models at each point in time, and the mechanisms that facilitate the transitions between phases in the emergence of a shared egovernment policy solution.
The empirical case and the process model presented in this study aim at providing a stepping stone for further unboxing the under-investigated relationship between dynamics and outcomes of public-private collaborations in e-government policies. We call for future research utilizing the process model in a comparative fashion, and categorizing different patterns of interaction between public and private actors in the emergence of e-government policies.

\section{References}

[1] Belachew, M. and Shyamasundar, R.K. Public private partnerships (PPP) in the e-government initiatives for developing nations: the case of Ethiopia. Proceedings of the 7th International Conference on Theory and Practice of Electronic Governance, ACM (2013), 42-45.

[2] Castro, D. Explaining International Leadership: Electronic Identification Systems. The Information Technology \& Innovation Foundation, September (2011).

[3] Cheng, M. and Yu, Y. Research on the Cooperation Optimization of Public-Private Partnership Based on Principal-Agent Theory. 2010 International Conference on E-Business and E-Government (ICEE), (2010), 2875-2877.

[4] Constantinides, P. and Barrett, M. Information Infrastructure Development and Governance as Collective Action. Information Systems Research 26, 1 (2014), 40-56.

[5] Corbin, J.M. and Strauss, A. Grounded theory research: Procedures, canons, and evaluative criteria. Qualitative Sociology 13, 1 (1990), 3-21.

[6] Danish Ministry of Finance. Effektiv EDB i staten ("Effective IT in State Administration"). Danish Ministry of Finance, Copenhagen, 1992.

[7] Eaton, B., Hallingby, H.K., Nesse, P.-J., and Hanseth, O. Achieving Payoffs from an Industry Cloud Ecosystem at BankID. MISQ Executive 13, 4 (2014), 223-235.

[8] Foray, D. Users, Standards and the Economics of Coalitions and Committees. Information Economics and Policy 6, 3-4 (1994), 269-293.

[9] Grasman, S.E., Faulin, J., and Lera-Lopez, F. PublicPrivate Partnerships for technology growth in the public sector. 2008 IEEE International Engineering Management Conference, (2008), 1-4.

[10] Grönlund, Å. Electronic identity management in Sweden: governance of a market approach. Identity in the Information Society 3, 1 (2010), 195-211.

[11] Hartley, J. Innovation in governance and public services: Past and present. Public money and management 25, 1 (2005), 27-34. 
[12] Hedman, J., Lind, M., Forsgren, O., and Albinsson, L. Business Models for Public Private Partnership: The 3P Framework. In Collaboration and the Knowledge Economy: Issues, Applications, Case Studies. IOS Press, Amsterdam, 2008.

[13] Hedström, K., Karlsson, F., and Söderström, F. Challenges of introducing a professional eID card within health care. Transforming Government: People, Process and Policy 10, 1 (2016), 26-46.

[14] Hoff, J.V. and Hoff, F.V. The Danish eID case: twenty years of delay. Identity in the Information Society 3, 1 (2010), 155-174.

[15] Johansson, S. Lokaldemokrati i informationsalderen. In Danmark som informationsamfund. Muligheder og barrierer for politik og demokrati. Aarhus Universitetsforlag, Aarhus, 2004, 226-250.

[16] Klein, S. and Schellhammer, S. Developing IOIS as Collective Action: A Cross-Country Comparison in the Health Care Sector. 2011 44th Hawaii International Conference on System Sciences (HICSS), (2011), 1-10.

[17] Klievink, B., Bharosa, N., and Tan, Y.-H. The collaborative realization of public values and business goals: Governance and infrastructure of public-private information platforms. Government Information Quarterly 33, 1 (2016), $67-79$.

[18] Klijn, E.-H. Governance and Governance Networks in Europe: An assessment of ten years of research on the theme. Public Management Review 10, 4 (2008), 505-525.

[19] Kubicek, H. Introduction: conceptual framework and research design for a comparative analysis of national eID Management Systems in selected European countries. Identity in the Information Society 3, 1 (2010), 5-26.

[20] Kubicek, H. and Noack, T. Different countries-different paths extended comparison of the introduction of eIDs in eight European countries. Identity in the Information Society 3, 1 (2010), 235-245.

[21] Kumar, N., Stern, L.W., and Anderson, J.C. Conducting Interorganizational Research Using Key Informants. Academy of Management Journal 36, 6 (1993), 1633-1651.

[22] Lentner, G.M. and Parycek, P. Electronic identity (eID) and electronic signature (eSig) for eGovernment services - a comparative legal study. Transforming Government: People, Process and Policy 10, 1 (2016), 8-25.

[23] Lyon, D. Identifying citizens: ID cards as surveillance. Polity Press, Cambridge, UK, 2009.

[24] Markus, M.L., Steinfield, C.W., Wigand, R.T., and Minton, G. Industry-wide Information Systems

Standardization As Collective Action: The Case of the U.S. Residential Mortgage Industry. MIS Quarterly 30, 1 (2006),
$439-465$.

[25] Maskin, E. and Tirole, J. Public-private partnerships and government spending limits. International Journal of Industrial Organization 26, 2 (2008), 412-420.

[26] Melin, U., Axelsson, K., and Söderström, F. Managing the development of e-ID in a public e-service context: Challenges and path dependencies from a life-cycle perspective. Transforming Government: People, Process and Policy 10, 1 (2016), 72-98.

[27] Ng, S.T., Wong, Y.M.W., and Wong, J.M.W. A Structural Equation Model of Feasibility Evaluation and Project Success for Public-Private Partnerships in Hong Kong. IEEE Transactions on Engineering Management 57, 2 (2010), 310-322.

[28] Nikayin, F. Common Platform Dilemmas: Collective Action and the Internet of Things. 2014.

[29] Nikayin, F., De Reuver, M., and Itälä, T. Collective action for a common service platform for independent living services. International Journal of Medical Informatics 82, 10 (2013), 922-939.

[30] OECD. NemID - Danish National eID and digital signature scheme. Observatory of Public Sector Innovation, 2016.

[31] Ojo, A. and Mellouli, S. Deploying governance networks for societal challenges. Government Information Quarterly, (2016).

[32] Oliver, P.E. and Marwell, G. Whatever happened to critical mass theory? A retrospective and assessment. Sociological Theory 19, 3 (2001), 292-311.

[33] Olson, M. The Logic of Collective Action: Public Goods and the Theory of Groups. Harvard University Press, Boston, 1965.

[34] Osborne, S.P. The new public governance: Emerging perspectives on the theory and practice of public governance. Routledge, London, 2010.

[35] Ostrom, E. Collective action and the evolution of social norms. Journal of Natural Resources Policy Research 6, 4 (2014), 235-252.

[36] Pettigrew, A.M. Contextualist research and the study of organizational change processes. In Doing Research that is Useful for Theory and Practice. Jossey Bass, San Francisco, CA, 1985.

[37] Ranerup, A., Henriksen, H.Z., and Hedman, J. An analysis of business models in Public Service Platforms. Government Information Quarterly 33, 1 (2016), 6-14.

[38] Rao, H., Morrill, C., and Zald, M.N. Power plays: How social movements and collective action create new 
organizational forms. Research in organizational behavior 22, (2000), 237-281.

[39] de Reuver, M., Verschuur, E., Nikayin, F., Cerpa, N., and Bouwman, H. Collective action for mobile payment platforms: A case study on collaboration issues between banks and telecom operators. Electronic Commerce Research and Applications 14, 5 (2015), 331-344.

[40] Seltsikas, P. and O'Keefe, R.M. Expectations and outcomes in electronic identity management: the role of trust and public value. European Journal of Information Systems 19, 1 (2010), 93-103.

[41] Taher, M., Yang, Z., and Kankanhalli, A. Public-Private Partnerships In E-Government: Insights From Singapore Cases. PACIS 2012 Proceedings, (2012), Paper 116.

[42] Van de Ven, A.H. and Poole, M.S. Explaining development and change in organizations. Academy of management review 20, 3 (1995), 510-540.

[43] Walsham, G. Interpretive case studies in IS research: nature and method. European Journal of Information Systems 4, 2 (1995), 74-81.
[44] Whitley, E.A., Gal, U., and Kjaergaard, A. Who do you think you are? A review of the complex interplay between information systems, identification and identity. European Journal of Information Systems 23, 1 (2014), 17-35.

[45] Whitley, E.A. and Hosein, I.R. Doing the politics of technological decision making: due process and the debate about identity cards in the U.K. European Journal of Information Systems 17, 6 (2008), 668-677.

[46] Wihlborg, E. Secure electronic identification (eID) in the intersection of politics and technology. International Journal of Electronic Governance 6, 2 (2013), 143-151.

[47] Wixom, B.H. and Watson, H.J. An Empirical Investigation of the Factors Affecting Data Warehousing Success. MIS Quarterly 25, 1 (2001), 17-41.

[48] Yin, R.K. Case study research: design and methods. Sage Publications, Newbury Park, 1994. 